\title{
Dejando una huella durante el servicio social
}

\author{
Rosa María del Ángel Martínez
}

\section{Resumen}

Como estudiante universitario, una de las oportunidades que se tiene para desarrollar el autoconocimiento, adquirir experiencias, conocer gente nueva y descubrir fortalezas y habilidades se da durante el servicio social. En este apartado, resaltamos la importancia que los prestadores de servicio social tienen para la Revista Digital Universitaria, así como algunas de las destrezas que se pueden adquirir y practicar al colaborar con nosotras.

Palabras clave: servicio social, redacción, revista digital, habilidad laboral.

\section{LEAVING A FOOTPRINT DURING SOCIAL SERVICE}

\section{Abstract}

As a college student, one of the opportunities you have to develop self-awareness, gain experiences, meet new people, and discover strengths and abilities occurs during social service. In this section, we highlight the importance that social service providers have for the University Digital Magazine, as well as some of the skills that can be acquired and practiced by collaborating with us.

Keywords: social service, writing, digital magazine, job skills. 
"Dejando una huella durante el servicio social" Rosa María del Ángel Martínez Vol. 22, Núm. 4, julio-agosto 2021 Revista Digital Universitaria

\section{Rosa María del Ángel Martínez}

rosa_martinez@cuaieed.unam.mx orcid.org/0000-0001-7655-0314

Estudió la licenciatura en Creación literaria y se ha especializado en la edición de revistas y libros electrónicos. Inició su formación profesional como becaria de la Revista Digital Universitaria (RDU), donde hizo la labor de corrección de estilo y maquetación de pdfs. Posteriormente, colaboró en el Proyecto de Digitalización del Acervo Histórico de la Revista de la Universidad de México y en el Proyecto de digitalización del Acervo Histórico de la Gaceta unAm, que corrieron a cargo del área de Acervos Digitales de la Dirección General de Tecnologías de la Información y Comunicaciones (DGTIC). Al mismo tiempo, colaboró en el Proyecto Universitario del Libro Electrónico para la Dirección General de Publicaciones y Fomento Editorial (DGPyFE), en el cual produjo y editó libros y tesis en formato ePub 2 y 3. Además, formó parte del equipo a cargo del proyecto Digitalización de las Obras Completas de Francisco Hernández. También, perteneció al equipo de Revistas unam en donde desempeñó actividades como: configuración de la plataforma ojs 2 y 3, asesorías a editores, autores y equipos editoriales para la gestión de la plataforma y seguimiento del proceso editorial de una revista electrónica. Asimismo, ha impartido talleres de producción y edición de eBook básico y avanzado como parte del Programa de Apoyo a la Profesionalización de la Actividad Editorial organizado por la DGPYFE. Actualmente funge como editora asociada de la Revista Digital Universitaria. 
"Dejando una huella durante el servicio social"

Rosa María del Ángel Martínez

Vol. 22, Núm. 4, julio-agosto 2021

Revista Digital Universitaria

Como estudiante universitario, se suelen adquirir muchos compromisos, uno de ellos es el aprovechar al máximo los estudios para obtener el título. Sin embargo, ir a la universidad también se trata de desarrollar el autoconocimiento a través de la adquisición de nuevas experiencias, de conocer gente nueva y de descubrir fortalezas y habilidades que no sabías que tenías. Y, sin duda, una de las oportunidades para desarrollarse en este ámbito es realizando el servicio social. Éste es una manera práctica de aprender nuevas habilidades en una empresa u organización aparte de las adquiridas en las aulas.

Además de conseguir una valiosa experiencia laboral, el servicio social te ayuda a entender si el campo o la industria en la que te gustaría trabajar es el correcto. Esto puede servir para evitar los costos de obtener un título en un campo que no es el adecuado o que no te interesa.

El servicio puede durar de unas pocas semanas a unos meses, con diferentes horas de trabajo, pero puede traer beneficios a largo plazo, como oportunidades de trabajo en la organización y un mayor conocimiento sobre el medio. Además, el supervisor y los colegas pueden ser una referencia para un trabajo, solicitudes universitarias o incluso para solicitudes de becas.

Es por esto que, a lo largo de sus 21 años, la Revista Digital Universitaria (RDU) ha abierto sus puertas a jóvenes que buscan ser productivos, ampliar sus horizontes y redes, y aplicar sus habilidades en proyectos tangibles. Por ello, alentamos a los prestadores de servicio social a encontrar diversas maneras de contribuir con tiempo y talento en las distintas actividades que se realizan en la revista.

Hacer el servicio social en la RDu es como andar en una calle de doble sentido: te beneficia a ti y beneficia a la comunidad universitaria. Uno de los objetivos de la revista es: "crear un espacio de comunicación y visibilización de los docentes y de los estudiantes como sujetos fundamentales en el quehacer académico de la universidad" (Revista Digital Universitaria [RDU], 2021). Así que, hacer el servicio en nuestra redacción significa comprometerse en una actividad compartida y conectarse a la comunidad universitaria desde otra arista: "es una actividad esencial que consolida la formación profesional y fomenta en el estudiante una conciencia de solidaridad con la comunidad, la sociedad y el país" (Universidad Nacional Autónoma de México [UNAM], 2018).

Que sirva este texto como carta de agradecimiento a todos los prestadores de servicio social que han colaborado con nosotros a lo largo de los 21 años de la RDU. Gracias por su talento, entusiasmo, tiempo y atención dedicados al cuidado de los contenidos, de las imágenes y de las cápsulas. Sin ustedes, la RDU no podría funcionar de la manera en la que lo hace. Esperamos que también se hayan llevado algo valioso o grato de nosotros. 
Video 1. Ana narra su experiencia como prestadora de servicio social en la RDU. Autoría de Ana Perla Ávila.

Video 2. Abi narra su experiencia como prestadora de servicio social en la RDU. Autoría de Abigail Barba.
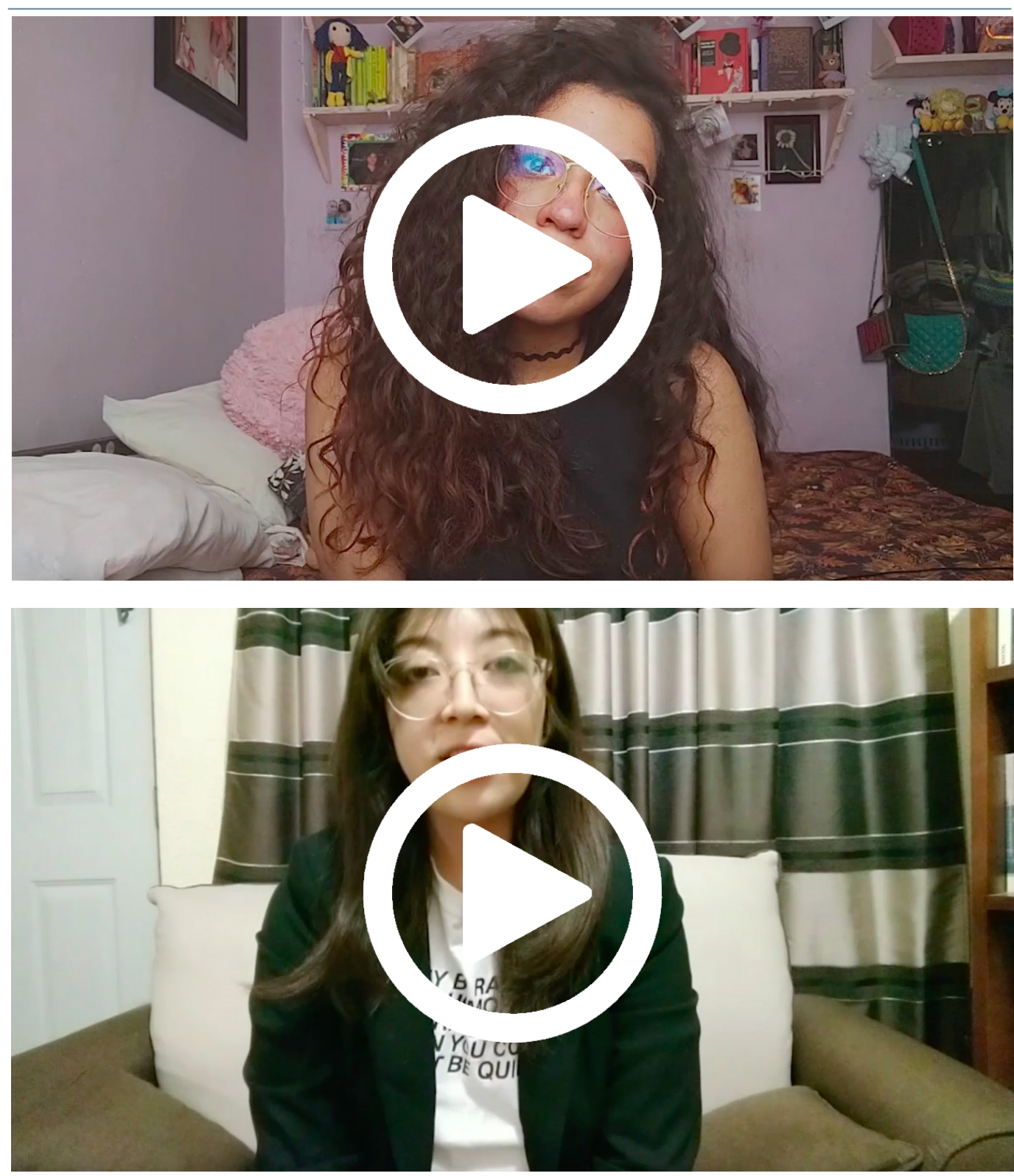

Referencias

Revista Digital Universitaria. (2021). Objetivos. https://www.revista.unam.mx/objetivos/

* Universidad Nacional Autónoma de México. (2018). Servicio Social Universitario. Introducción. https://www.dgoserver.unam.mx/portaldgose/servicio-social/htmls/ssuniversitario/ssu-introduccion.html

\section{Cómo CITAR ESTE ARTículo}

* del Ángel Martínez, Rosa María. (2021, julio-agosto). Dejando una huella durante el servicio social. Revista Digital Universitaria (RDU), 22(4). http://doi.org/10.22201/ cuaieed.16076079e.2021.22.4.14. 